OPEN ACCESS

Edited by:

Michael Ming-Yuan Wei, Texas Commission on Environmental

Quality, United States

Reviewed by:

Rocktotpal Konwarh,

Addis Ababa Science and Technology

University, Ethiopia

Raviraj Vankayala,

Independent Researcher,

Irvine, United States

*Correspondence:

Xiyun Yan

yanxy@ibp.ac.cn

Minmin Liang

mmliang@bit.edu.cn

tThese authors have contributed equally to this work

Specialty section:

This article was submitted to Nanobiotechnology,

a section of the journal

Frontiers in Bioengineering and

Biotechnology

Received: 28 September 2019

Accepted: 09 January 2020

Published: 06 February 2020

Citation:

Wang P, Wang T, Hong J, Yan X and Liang M (2020) Nanozymes:

A New Disease Imaging Strategy.

Front. Bioeng. Biotechnol. 8:15.

doi: 10.3389/fbioe.2020.00015

\section{Nanozymes: A New Disease Imaging Strategy}

\author{
Peixia Wang ${ }^{1,2,37}$, Tao Wang ${ }^{4 t}$, Juanji Hong ${ }^{2}$, Xiyun Yan ${ }^{1,3 *}$ and Minmin Liang $^{2 \star}$ \\ ${ }^{1}$ CAS Engineering Laboratory for Nanozyme, Key Laboratory of Protein and Peptide Pharmaceutical, Institute of Biophysics, \\ Chinese Academy of Sciences, Beijing, China, ${ }^{2}$ Experimental Center of Advanced Materials School of Materials Science \& \\ Engineering, School of Materials Science \& Engineering, Beijing Institute of Technology, Beijing, China, ${ }^{3}$ College of Life \\ Sciences, University of Chinese Academy of Sciences, Beijing, China, ${ }^{4}$ Department of Neurosurgery, Peking University Third \\ Hospital, Beijing, China
}

Nanozymes are nanomaterials with intrinsic enzyme-like properties. They can specifically catalyze substrates of natural enzymes under physiological condition with similar catalytic mechanism and kinetics. Compared to natural enzymes, nanozymes exhibit the unique advantages including high catalytic activity, low cost, high stability, easy mass production, and tunable activity. In addition, as a new type of artificial enzymes, nanozymes not only have the enzyme-like catalytic activity, but also exhibit the unique physicochemical properties of nanomaterials, such as photothermal properties, superparamagnetism, and fluorescence, etc. By combining the unique physicochemical properties and enzyme-like catalytic activities, nanozymes have been widely developed for in vitro detection and in vivo disease monitoring and treatment. Here we mainly summarized the applications of nanozymes for disease imaging and detection to explore their potential application in disease diagnosis and precision medicine.

Keywords: nanozyme, natural enzyme, disease imaging, precision medicine, tumor

\section{INTRODUCTION}

Nanozyme is a new type of artificial enzyme with intrinsic enzyme-like characteristics. In 2007, we reported the landmark paper that $\mathrm{Fe}_{3} \mathrm{O}_{4}$ nanoparticles (NPs) have intrinsic peroxidase-like activity (Gao et al., 2007), and since that time nanozymes have increasingly attracted attention from a broad spectrum of scientists and technologists because of their high catalytic activity, low cost, and high stability (Gao and Yan, 2016). To date, there are more than 300 types of nanomaterials that have been found to possess the intrinsic enzyme-like activity, including the peroxidase activity of $\mathrm{Fe}_{3} \mathrm{O}_{4}$ (Gao et al., 2007), $\mathrm{Co}_{3} \mathrm{O}_{4}$ (Mu et al., 2012), $\mathrm{CuO}$ (Liu et al., 2014), $\mathrm{V}_{2} \mathrm{O}_{5}$ (André et al., 2011), $\mathrm{MnFeO}_{3}$ (Chi et al., 2018), FeS (Dai et al., 2009), graphene quantum dots (Nirala et al., 2017), $\mathrm{CeO}_{2}$ (Xue et al., 2012), $\mathrm{BiFeO}_{3}$ (Wei et al., 2010), $\mathrm{CoFe}_{2} \mathrm{O}_{4}$ (He et al., 2010), FeTe (Roy et al., 2012), gold@carbon dots (Zheng et al., 2016); oxidase activity of Au (Comotti et al., 2004), $\mathrm{Pt}$ (Yu et al., 2014), $\mathrm{CoFe}_{2} \mathrm{O}_{4}$ (Zhang et al., 2013), $\mathrm{MnO}_{2}$ (Xing et al., 2012), $\mathrm{CuO}$ NPs (Hu et al., 2017) and $\mathrm{NiCo}_{2} \mathrm{O}_{4}$ (Su et al., 2017); catalase activity of $\mathrm{CeO}_{2}$ NPs (Talib et al., 2010), Pt-Ft NPs (Fan et al., 2011), Ir NPs (Su et al., 2015), MoS 2 nanosheets (Chen et al., 2018), Prussian Blue NPs (Zhang W. et al., 2016); superoxide oxidase activity of $\mathrm{CeO}_{2}$ (Tarnuzzer et al., 2005), Fullerene (Ali et al., 2004), $\mathrm{FePO}_{4}$ microflowers (Wang W. et al., 2012), Gly-Cu (OH) 2 NPs (Korschelt et al., 2017), N-PCNs (Fan et al., 2018); haloperoxidase activity of $\mathrm{V}_{2} \mathrm{O}_{5}$ nanowire (Natalio et al., 2012), $\mathrm{CeO}_{2 \mathrm{x}}$ Nanorods (Herget et al., 2017); sulfite oxidase activity of $\mathrm{MoO}_{3} \mathrm{NPs}$ (Ragg et al., 2014); phosphatase activity of $\mathrm{CeO}_{2}$ (Kuchma et al., 2010), $\mathrm{Fe}_{2} \mathrm{O}_{3}$ NPs (Huang, 2018); phosphotriesterase 


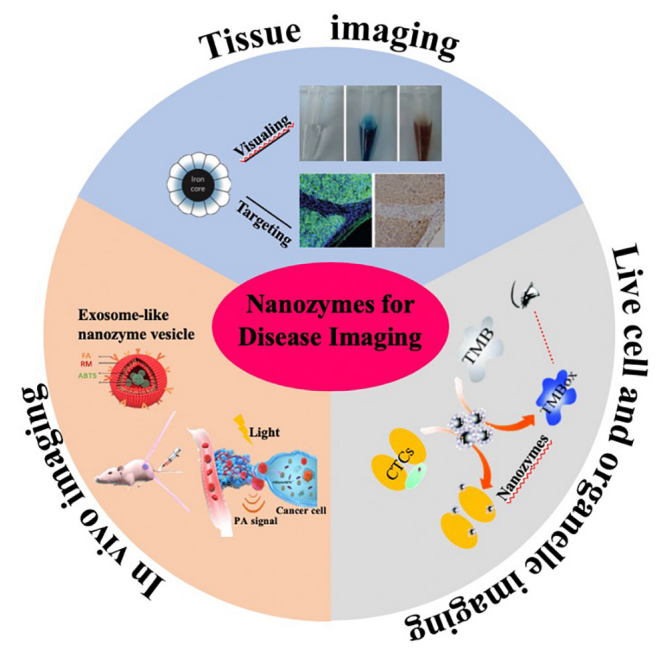

GRAPHICAL ABSTRACT | Nanozymes for disease imaging and diagnosis. Adapted with permission from Fan et al. (2012), Li et al. (2017), Ding et al. (2019).

activity of $\mathrm{Co}_{3} \mathrm{O}_{4} / \mathrm{GO}$ nanocomposites (Wang et al., 2017), $\mathrm{CeO}_{2}$ NPs (Vernekar et al., 2016), MOF-808 ( $\mathrm{M}=\mathrm{Zr}$ ) (Mondal and Holdt, 2016), UiO-66@LiOtBu ( $\mathrm{M}=\mathrm{Zr}$ ) (Mondal and Holdt, 2016); $\mathrm{CO}$ oxidase activity of $\mathrm{Cu}_{2} \mathrm{O} @ \mathrm{CeO}_{2}$ core@shell nanocubes (Wang et al., 2015); chymotrypsin activity of Cr-MIL-101 (Nath et al., 2016); G-selective DNA cleaving activity of fullerene carboxylic acid (Tokuyama et al., 1993); protease activity of Cu-MOF (Li et al., 2014); restriction endonuclease activity of CdTe NPs (Sun et al., 2018); carbonic anhydrase activity of CoBBP@Tb-MOF (Sahoo et al., 2013), etc. With the emergence of the new concept of "nanozymology" (Jiang B. et al., 2018), "Nanozymes" have now become an emerging new field bridging nanotechnology and biology.

As a new type of promising artificial enzymes, nanozymes have shown a broad spectrum of applications because of their obvious advantages including high stability, high catalytic activity, low cost, large surface area for functionalization, and tunable activity. In particular, by combining their unique physicochemical properties (such as fluorescence, X-ray absorption, and paramagnetic properties, etc.), nanozymes have been widely explored from in vitro detection (Leng et al., 2009; Liang et al., 2010; Roy et al., 2012) to in vivo disease imaging and therapy (Hyon Bin et al., 2010; Yang et al., 2012; Kwon et al., 2016; Singh et al., 2017; Fan et al., 2018). In this review, we summarized the progress of nanozymes in disease detection and imaging, and discussed the current challenges and future directions of nanozyme development in disease imaging and diagnosis.

\section{NANOZYMES FOR PATHOLOGICAL DISEASE DIAGNOSIS}

Peroxidase nanozymes catalyze the oxidation of colorimetric substrates, such as 3,3,5,5-tetramethylbenzidine (TMB), diazo-aminobenzene (DAB), and o-phenylenediamine (OPD), to give a color reaction that can be used for imaging the recognized biomarkers within tissue sections for pathological disease diagnosis (Figure 1A). In 2012, Our group developed a magnetoferritin nanozyme (M-HFn) which is composed of a recombinant human heavy-chain ferritin (HFn) protein nanocage encapsulated an iron oxide nanocore for tumor targeting and imaging (Fan et al., 2012). HFn nanocage specifically recognized tumor cells via binding to overexpressed transferrin receptor 1 (TfR1) in tumor cells. Iron oxide nanocores catalyzed the oxidation of color substrates in the presence of $\mathrm{H}_{2} \mathrm{O}_{2}$ to produce an intense color reaction for visualizing tumor tissues. We examined 474 clinical human specimens including 247 clinical tumor tissues and 227 normal tissues and demonstrated that M-HFn nanozymes could identify nine types of cancer cells with a specificity of over $95 \%$ and sensitivity of $98 \%$. The concentration of M-HFn was $1.8 \mu \mathrm{M}$, and the reactive time was $1 \mathrm{~h}$ for DAB staining (Figure 1B). Likewise, Gu's groups developed avastin antibody-functionalized $\mathrm{Co}_{3} \mathrm{O}_{4}$ nanozymes as target-specific peroxidase mimics for immunohistochemical staining of vascular endothelial growth factor (VEGF) in tumor tissues and the concentration of $\mathrm{Ab}-\mathrm{Co}_{3} \mathrm{O}_{4}$ was $15 \mu \mathrm{g} / \mathrm{ml}, 100 \mu \mathrm{L}$, and the reactive time was 30 min for DAB staining (Dong et al., 2014). Due to the high peroxidase-like activity, $\mathrm{Co}_{3} \mathrm{O}_{4}$ nanozyme has been proved to be a potential label in place of natural enzymes. So far, numerous of peroxidase nanozyme-based staining methods have been developed for pathological diagnosis of breast cancer, colorectal, stomach, and pancreas (Zhang T. et al., 2016), hepatocellular carcinoma ( $\mathrm{Hu}$ et al., 2014; Jiang et al., 2019), esophageal cancer (Wu et al., 2011), and bladder cancer (Peng et al., 2019).

By compare with the traditional immunohistochemistry, the nanozyme-based pathological staining method is more rapid and sensitive because of their higher catalytic activity than natural enzymes [e.g., horseradish peroxidase (HRP)], which greatly shortens the diagnostic time and reduces the cost and thus has significant implications for clinical pathological diagnosis. In addition, besides tumor pathological diagnosis, peroxidase nanozymes have also been used for pathological identification of human high-risk and ruptured atherosclerotic plaques (Wang et al., 2019). M-HFn nanozymes specifically distinguish the ruptured and high-risk plaque tissues via TfR1, which is highly expressed in plaque-infiltrated macrophages and significantly associated with the increasing risk of plaque rupture. As shown Figure 1C, M-HFn peroxidase nanozymes could specifically distinguish high-risk plaque tissues from patients with symptomatic carotid disease, and M-HFn staining showed a significant correlation with plaque vulnerability $(r=0.89, P<0.0001)$.

To further improve the detection sensitivity of nanozymebased pathological staining method, much effort has been expended to improve the enzyme-like catalytic activity of nanozymes, including adjusting their size, shape, composition, surface modification, and heteroatomic doping (Dong et al., 2014; Zhang et al., 2017; Jiang et al., 2019; Li et al., 2019). In 
A

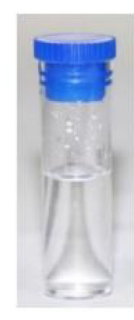

\section{Peroxidase nanozymes}

HAc/NaAc buffer, pH 3.6

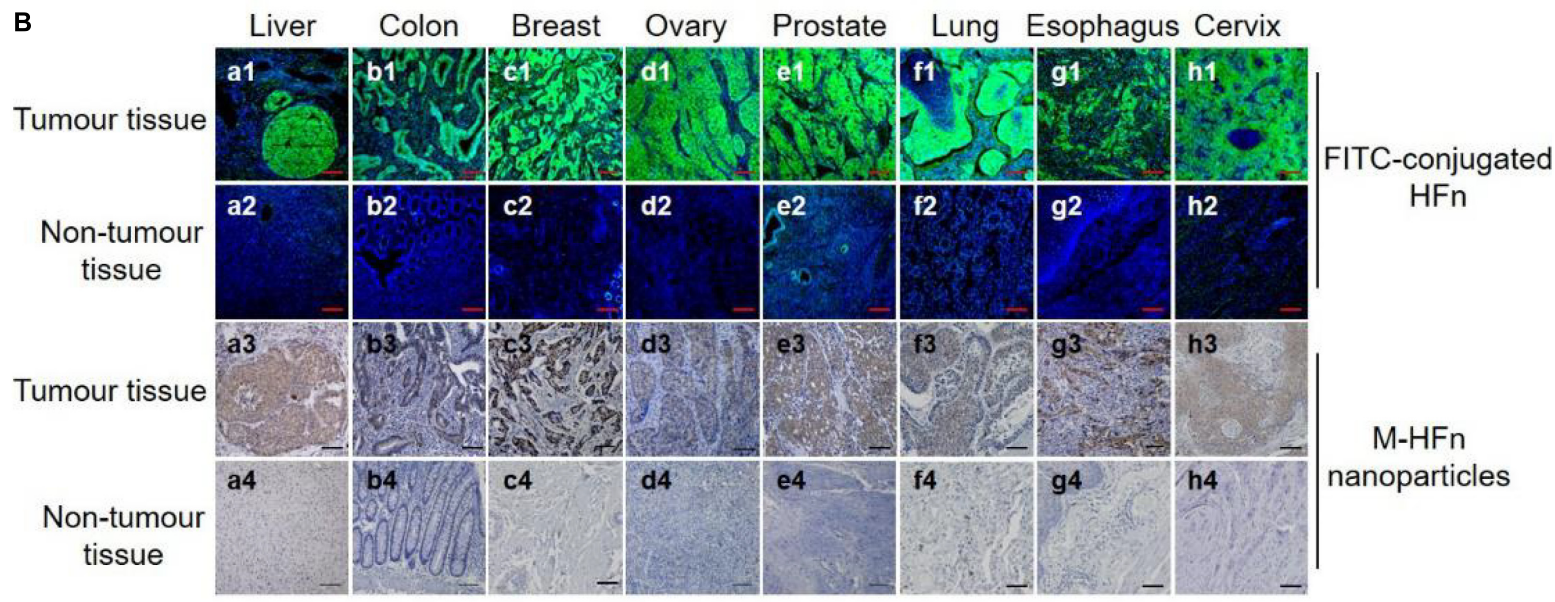

C
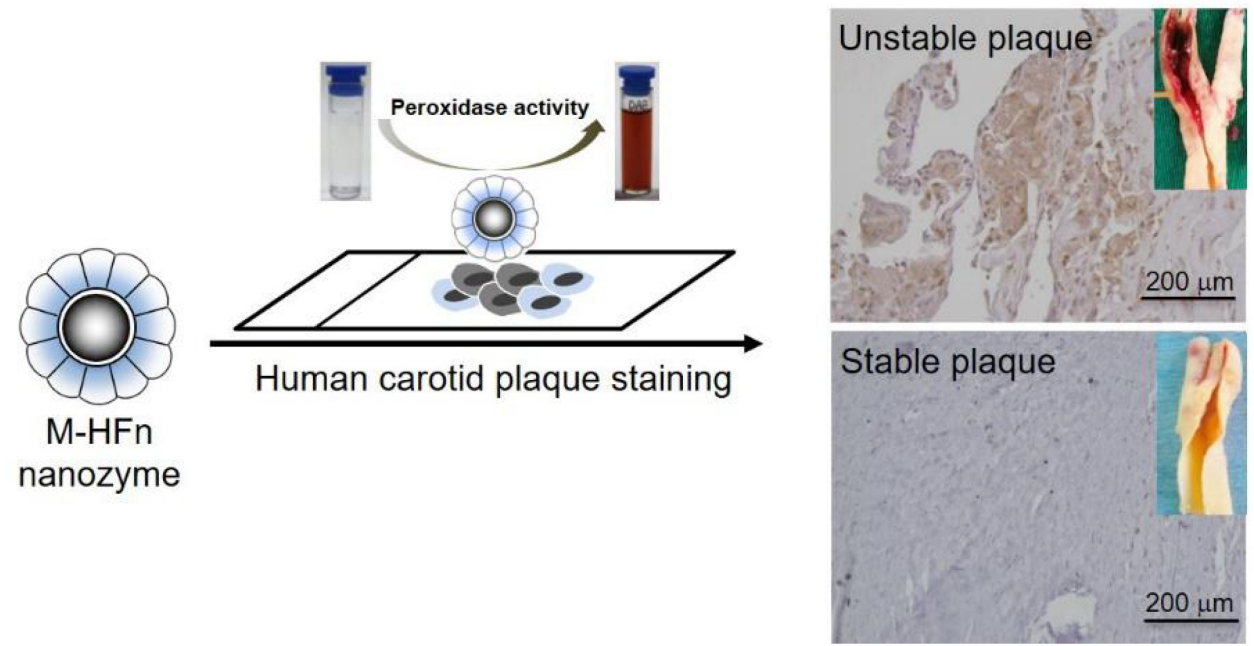

FIGURE 1 | Nanozymes for pathological tissue imaging. (A) Peroxidase nanozymes catalyze the oxidation of various peroxidase substrates (TMB, DAB, and OPD) in the presence of $\mathrm{H}_{2} \mathrm{O}_{2}$ to produce different color reactions. Adapted with permission from ref (Jiang B. et al., 2018), () 2018, Springer Nature. (B) M-HFn nanozymes specifically stained tumor tissues from different organs. Adapted with permission from ref (Fan et al., 2012), () 2012, Springer Nature. (C) Peroxidase nanozymes for the pathological identification of unstable atherosclerotic plaques from patients with symptomatic carotid disease. Reproduced with permission from ref (Liang and Yan, 2019), () 2019, American Chemical Society.

2018, Leong and co-workers engineered a mesoporous silicagold nanocluster hybrid nanozymes with excellent peroxidaselike catalytic activity for selective detection of HER2-positive $\left(\mathrm{HER}^{2+}\right.$ ) breast cancer cell (Li et al., 2019). Owing to their high catalytic performance, the prepared silica-gold hybrid nanozymes achieved the detection limit of 10 cells using colorimetric analysis. The hybrid nanozymes did not stain, or only slightly stained, normal or lesion tissues, but strongly stained cancerous regions. Significantly, there was a clear distinction between cancerous cells and adjacent normal cells in representative sections (Figure 2A).

Besides enzyme-like activity, the unique physicochemical properties (such as luminescence, X-ray absorption, and paramagnetic properties) of nanozymes also have been widely 

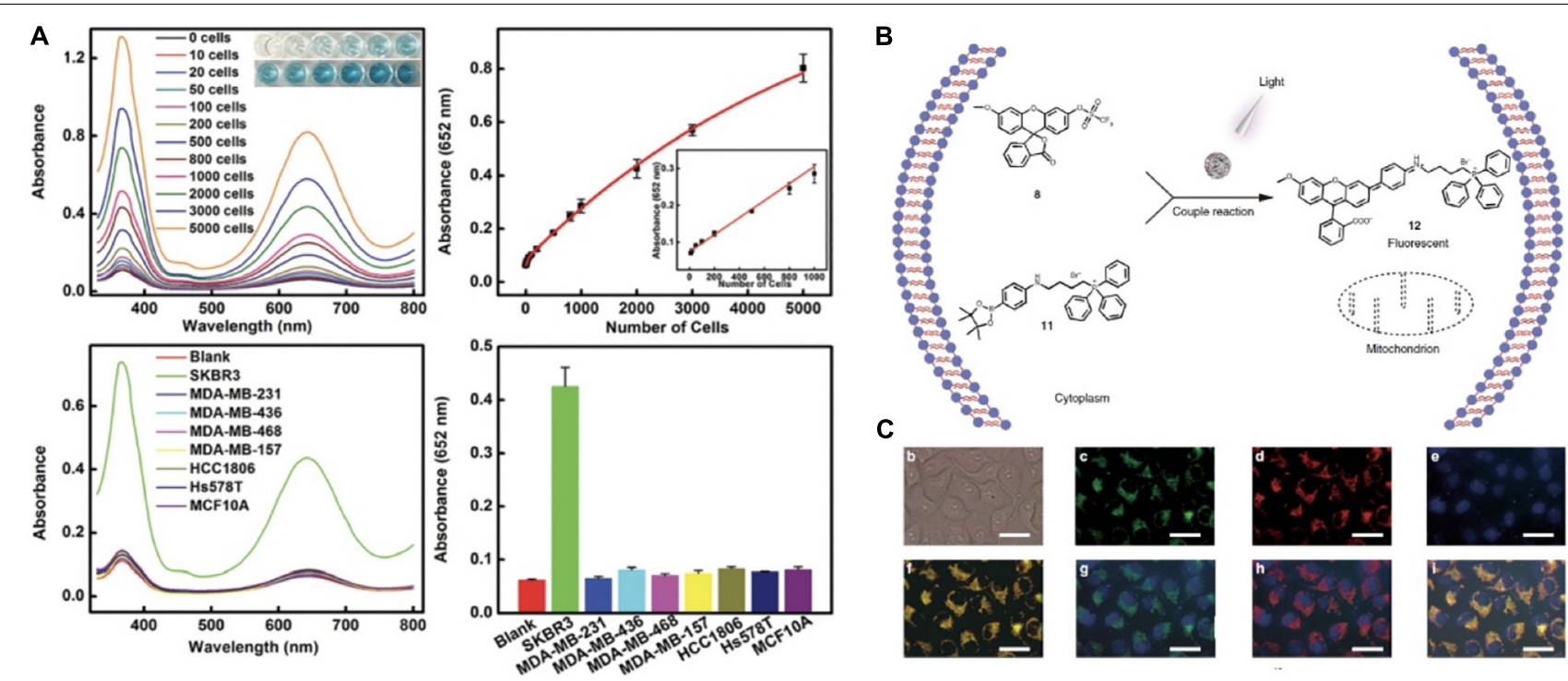

FIGURE 2 | Nanozymes for live cell and organelle imaging. (A) A multifunctional mesoporous silica-gold nanozyme platform for selective breast cancer cell detection using a catalytic amplification-based colorimetric assay. Reproduced with permission from ref (Li et al., 2019), (C) 2019, The Royal Society of Chemistry. (B) Scheme of nanozyme-based methods for mitochondrial fluorescent imaging. (C) Representative nanozyme-based light-mediated reversible catalysis for mitochondrial imaging. Adapted with permission from ref (Wang et al., 2018).

developed for pathological tissue imaging. For instance, Cai's group developed a folate receptor-targeting gold nanocluster as fluorescence enzyme mimetic nanoprobes for tumor tissues fluorescence visualizing detection. In the work, the intravenous dose used was $500 \mathrm{mg} / \mathrm{kg}$ for fluorescence imaging, and the concentration of $1.8 \mathrm{mM}, 1 \mathrm{~h}$ was used for DAB staining (Hu et al., 2014). For the same tumor tissue slice, nanozyme staining and fluorescent staining were obtained simultaneously in a one-step incubation, and the results were mutually complementary. Thus, the developed fluorescence/nanozyme nanoprobes could provide a molecular colocalization diagnosis strategy within clinical tissue specimens, which efficiently avoids false-positive and falsenegative results, and greatly improves the detection accuracy, credibility, and repeatability for cancer pathological diagnoses. Likewise, Zhang et al., also developed a gold nanozyme-based dark-field imaging assay as a novel immunohistochemical method for detecting HER2 overexpressed in breast cancer tissues (Lin et al., 2016). By quantitative analysis of the optical property of dark-field imaging, cancerous tissue can be quantitatively divided into four levels: ",,-+++ , and ++ ."

Despite the fact that nanozyme-based staining methods have been broadly developed for pathological disease diagnosis, there are still many unresolved issues and challenges. The first is how to improve the enzyme-like activity of nanozymes. Since the catalytic activity of nanozymes is directly correlated with their detection sensitivity, the improvement of enzymelike activity of nanozymes could help substantially improve the detection sensitivity of nanozyme-based staining methods. However, the issue of false positives would arise along with the improved enzyme-like activity (Wu et al., 2019).
In addition, the false positive issue would become even more severe due to the limited substrate specificity of nanozymes. We proposed a strategy to improve both the catalytic activity and the substrate specificity by introducing histidine residues onto the surface of $\mathrm{Fe}_{3} \mathrm{O}_{4}$ nanozymes to mimic the natural peroxidase enzymes (Fan et al., 2017). Juewen Liu engineered a specific nanozyme using molecular imprinting method to enhance the substrate selectivity and activity of enzyme mimics (Zhang et al., 2017). In addition, the oriented immobilization of the recognizing moieties to the surface of nanozymes could also reduce false positives greatly. Guo et al., constructed an inorganic/protein hybrid nanozyme by oriented immobilizing nature enzymes on the surface of inorganic graphene NPs (Liu Y. et al., 2019). The prepared nanohybrid nanozymes exhibited outstanding peroxidase-mimicking activity and excellent substrate selectivity. The second challenge for nanozyme staining method is how to quantically analyze the pathological staining results. Currently, the clinical pathological analysis mainly relies on experienced judgment, which is subjective, and variation between observers is high for certain categories of pathological diagnosis (Qian and Jiao, 2017). By combining the unique optical property and enzyme-like catalytic activities, nanozymes hold promise to achieve quantitative analysis for pathological disease staining diagnosis.

\section{NANOZYMES FOR LIVE CELL AND ORGANELLE IMAGING}

Cytological examination is an important means of clinical disease diagnosis (Bromberg et al., 2007; Mosterd et al., 2008; 


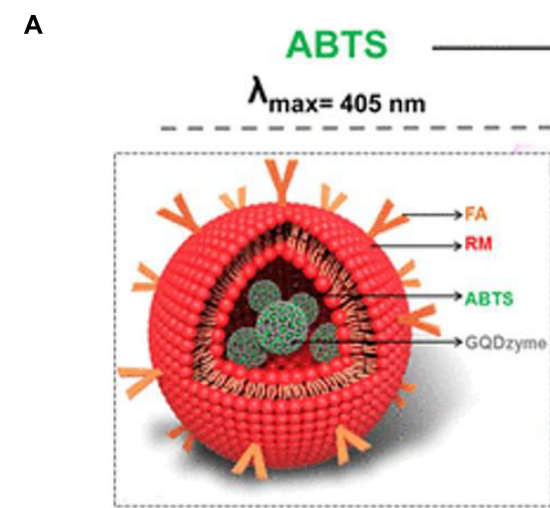

Exosome-like nanozyme vesicle

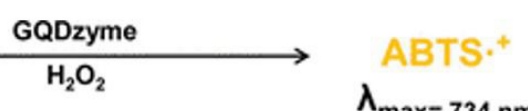

$\lambda_{\max }=734 \mathrm{~nm}$

B
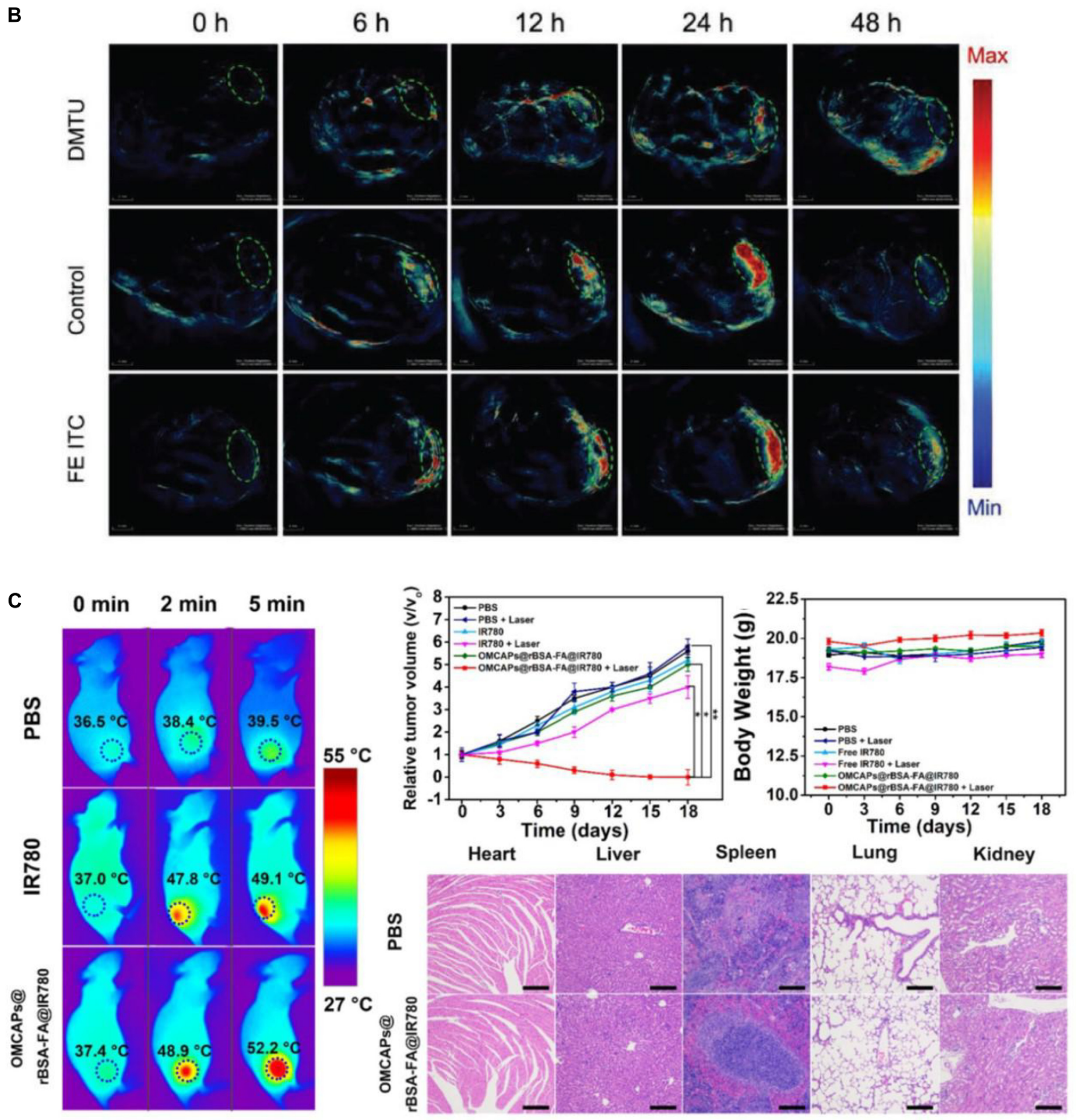

FIGURE 3 | Nanozymes for in vivo imaging of disease progression. (A) Schematic illustration of exosome-like nanozyme vesicles for the $\mathrm{H}_{2} \mathrm{O}_{2}$-responsive catalytic photoacoustic imaging of tumors. Reproduced with permission from ref (Ding et al., 2019), () 2019, American Chemical Society. (B) Representative nanozyme-based tumor photoacoustic imaging images. Reproduced with permission from ref (Liu F. et al., 2019), @ 2019, John Wiley and Sons. (C) Carbon-gold hybrid nanozymes for real-time imaging, photothermal/photodynamic and nanozyme oxidative therapy of tumors. Reproduced with permission from ref (Zhang et al., 2019). 
Hao et al., 2011; Venugopal and Prasad, 2015). Exfoliated cells from blood, cerebrospinal fluid, spinal fluid, chest water and mucous liquid can provide a large amount of clinical information (including cell morphology, cell type, and cell proportion, etc.), which can be used for cancer screening (Schiffman et al., 2000; Dillner et al., 2008), CNS hematologic malignancies (Bromberg et al., 2007) anemia diagnosis (Hao et al., 2011), and Langerhans cell granulomatosis detection (Mosterd et al., 2008).

Currently, the most commonly used cytological detection methods are flow cytometry, cytological smear and nucleic acid testing. These traditional methods are characterized by high technical requirements, time consuming or high cost. Nanozymes-driven color reaction can be used for qualitative and quantitative analysis of cytological features. Trau et al. extended the application of nanozymes to the detection of circulating tumor cells (CTCs) (Li et al., 2017). The targeting antibody-conjugated $\mathrm{Fe}_{3} \mathrm{O}_{4}$ nanozymes simultaneously achieved CTC magnetic isolation and visualization by catalyzing the oxidation of colorimetric substrate TMB into blue colored products. In addition, the visualized CTCs can be further quantified using UV-vis measurement. The developed nanozyme platform successfully detected 13 melanoma CTCs per $\mathrm{mL}$ blood within $50 \mathrm{~min}$, and the concentration of $\mathrm{Fe}_{3} \mathrm{O}_{4}$ nanozymes used was about $0.2 \mathrm{mg} / \mathrm{ml}$ for TMB colorimetric development. Later, Wang et al. (2018) also developed an $\mathrm{Fe}_{3} \mathrm{O}_{4}$ NPs-based ultrasensitive electrochemical CTCs detection strategy (Tian et al., 2018). Under the optimized experimental conditions, the proposed nanozyme cytosensor exhibited significant analytical performance for MCF-7 CTCs detection with a detection limit of 6 cells $\mathrm{mL}^{-1}$ with a linear range from 15 to 45 cells $\mathrm{mL}^{-1}$ at the acceptable stability condition and reproducibility. Recently, nanozyme-based detection strategies have been broadly developed for the cytological detection of breast cancer cell ( $\mathrm{Li}$ et al., 2019), cervical cancer cells (Yu et al., 2013; Maji et al., 2015), human chronic myelogenous leukemia cell (Ge et al., 2014), melanoma tumor cell ( $\mathrm{Li}$ et al., 2017), and squamous cancer (Wang et al., 2014) etc.

In addition to detecting CTCs, researchers also employed the catalytic activity of nanozymes to design real-time detection probes for organelle imaging in living cells. For example, $\mathrm{Qu}$ et al., designed a heterogeneous palladium nanozyme that could effectively mediate the bioorthogonal reactions in situ through light and thus realized the specific imaging of mitochondria in living cells (Wang et al., 2018) (Figures 2B,C). Beside CTCs and organelle imaging detection, there are also several other nanozymes-based colorimetric methods for specific disease imaging, including jaundice (Santhosh et al., 2014), acquired immune deficiency syndrome (Lin et al., 2017), diabetes (Tianran et al., 2014), infectious disease (Kim et al., 2014; Duan et al., 2015), and neurodegenerative disease (Wang C. I. et al., 2012; Farhadi et al., 2014). Thus, compared to traditional methods (such as PCR, cell flow cytometry, and ELISA), nanozymes methods exhibit more broaden prospect for live cell and organelle imaging because nanozyme assay is more fast, cost-effective and much easier to operate.

\section{NANOZYMES FOR IN VIVO IMAGING}

In addition to enzyme-mimicking activity, nanozymes also exhibit fluorescence, electricity, paramagnetic properties and other unique physicochemical properties. By employing the unique physicochemical properties, nanozymes also have been broadly developed for in vivo monitoring and imaging of disease. For example, we utilized the unique $r 2$ relaxivity of iron nanozymes and achieved tumor in vivo magnetic resonance imaging (MRI) after we achieved the in vitro tumor tissue imaging by using the peroxidase-like activity of iron-based nanozymes with a single-dose of ${ }^{125} \mathrm{I}-\mathrm{M}-\mathrm{HFn}$ NPs containing $45 \mu \mathrm{g} \mathrm{HFn,} 500 \mu \mathrm{Ci}{ }^{125} \mathrm{I}$, and $11.2 \mu \mathrm{g} \mathrm{Fe}$ by intravenously injection (Zhao et al., 2016). We also designed a quantum-dot-based nanozyme vesicle for in vivo $\mathrm{H}_{2} \mathrm{O}_{2}$ responsive catalytic photoacoustic imaging of nasopharyngeal carcinoma (Ding et al., 2019). In this work, graphene quantum dots showed intense peroxidase activity and effectively catalyzed the peroxidase substrate 2,2'-azino-bis (3-ethylbenzthiazoline6-sulfonic acid) diammonium salt (ABTS) into its oxidized form. The oxidized ABTS then exhibited strong near-infrared (NIR) absorbance, rendering it to be an ideal contrast agent for photoacoustic imaging. In the study, GQDzyme was at a dose of $100 \mu \mathrm{g} / \mathrm{mL}, 100 \mu \mathrm{L}$ by an intravenously injection (Figure 3A). Jiang X. et al. (2018) achieved tumor phototherapy and simultaneous photoacoustic/thermal imaging and computed tomography by using a developed iridium oxide catalase nanozyme with extraordinary photothermal conversion efficiency and X-ray absorption coefficient showing a typical example of fully exploiting the multifunctional properties of nanozymes for tumor imaging and treatment. The BSA- $\mathrm{IrO}_{2} \mathrm{NPs}$ used in the study was $1.5 \mathrm{mM}, 200 \mu \mathrm{L}$ via an intravenously injection (Jiang X. et al., 2018).

Nanozyme probes have also been broadly developed for disease therapeutic monitoring. For example, in 2019, Chen's group prepared a tumor-microenvironment-activated nanozyme-mediated theranostic nanoreactor for imaging-guided combined tumor therapy (Liu F. et al., 2019). In their work, the constructed activatable nanoreactors achieved non-invasive imaging of tumor progression by using nanozyme-mediated photoacoustic imaging signal and photothermal therapy (PTT) function and the AMP NPs were at a dose of $10 \mathrm{mg} / \mathrm{kg}$, $200 \mu \mathrm{L}$ (Figure 3B). Cui's group also prepared a mesoporous carbon-gold hybrid nanozyme probe for real-time imaging, photothermal/photodynamic and nanozyme oxidative therapy of tumors (Zhang et al., 2019). The results demonstrated that the synthesized nanozyme probes revealed excellent tumor targeting efficacy, long tumor retention, and favorably diagnostic and therapeutic effect for tumor (Figure 3C).

Besides cancer imaging diagnosis, nanozymes also have been broadly exploited for many other disease imaging such as infections, inflammation and some neurological diseases. For example, Rotello et al., reported a gold NPs-based chargeswitchable nanozyme for bioorthogonal imaging of biofilmassociated infections (Tonga et al., 2015). In this work, the developed gold nanozymes could penetrate and accumulate inside the acidic microenvironment of biofilms and achieved 
imaging detection of the biofilm-associated infections arising from different and/or mixed bacteria species. Zhao et al. fabricated $\mathrm{MnO}_{2}$ nanozymes as the intracellular catalytic DNA circuit generators for versatile imaging of DNA base-excision repair in living cells (Chen et al., 2017). $\mathrm{MnO}_{2}$ nanosheet was used not only as a DNA nano-carrier but also a DNAzyme cofactor supplier. In this study, DNAzyme strands are blocked via the hybridization with the damaged bases-containing excision probes, which could be recognized by the corresponding baseexcision repair enzymes in living cell. The detection signal could be 40 -fold amplified by integrating several sets of probes with a dose of $20 \mu \mathrm{g} \mathrm{mL}^{-1} \mathrm{MnO}_{2}$ nanozymes. Likewise, Yang et al. (2018) reported a nanozyme tag enabled chemiluminescence imaging probe for simultaneous multiplex imaging of cytokines. The prepared chemiluminescence nanozyme probe provides a novel and universal nanozyme-labeled multiplex immunoassay strategy for high-throughput detection of relevant biomarkers and further disease diagnosis. Thus, nanozymes open novel avenues for monitoring the initiation and progress of diseases by combining the unique physicochemical properties and enzymelike catalytic activities of nanozymes.

\section{SUMMARY AND OUTLOOK}

The emergence of nanozymes uncovers the biological effects of inorganic nanomaterials. Nanozymes thus can be used as an alternative of natural enzymes because of their capability to address the limitations of natural enzymes such as low stability, high cost, and difficult storage. Over the past decade, nanozyme-based probes have been widely developed for disease imaging and diagnosis from in vitro to in vivo. The typical nanozymes for disease imaging diagnosis are summarized in Supplementary Table S1.

Despite the remarkable advantages of nanozymes, there still remains plenty of limitations while put nanozymes into practical clinical application, such as poor dispersibility, easy sedimentation after surface modification, limited catalytic types, poor substrate selectivity, and potential nanotoxicity. To further drive the rapid development of nanozyme-based imaging agents for disease diagnosis, substantial breakthroughs are expected by overcoming the following challenges: (1) Rational design and surface modification are still remain critical challenges to improve their substrate selectivity and

\section{REFERENCES}

Ali, S. S., Hardt, J. I., Quick, K. L., Kim-Han, J. S., Erlanger, B. F., Huang, T. T., et al. (2004). A biologically effective fullerene (C60) derivative with superoxide dismutase mimetic properties. Free. Radic. Biol. Med. 37, 1191-1202. doi: 10.1016/j.freeradbiomed.2004. 07.002

André, R., Natálio, F., Humanes, M., Leppin, J., Heinze, K., Wever, R., et al. (2011). $\mathrm{V} 2 \mathrm{O} 5$ nanowires with an intrinsic peroxidase-like activity. Adv. Funct. Mater. 21, 501-509. doi: 10.1002/adfm.201001302

Bromberg, J. E. C., Breems, D. A., Kraan, J., Bikker, G., van der Holt, B., Smitt, P. S., et al. (2007). CSF flow cytometry greatly improves diagnostic accuracy in dispersibility of nanozymes. Thus, both experimental and computational studies should be combined together to aid in the process of nanozyme design and surface modification. (2) A detailed understanding of the relationship between the catalytic properties and the in vivo biological behaviors of nanozymes is necessary. It is because the size, morphology and surface property of nanozymes have a direct impact on their catalytic activity and thus determine the in vivo biological behaviors of nanozymes. (3) A systematic evaluation of the biological fates and the biocompatibility of nanozyme systems (including the cytotoxicity, in vivo uptake and behavior, biodistribution, immunogenicity, blood compatibility, and tissue compatibility) should be performed when administrated into living organisms, since the biocompatibility and biodegradability are the common concerns when move these systems into clinical practice. (4) Developing standards and reference materials. Although nanozymes have shown a broad range of applications from in vitro biological detection to in vivo imaging diagnosis, there are rare basic concepts and the corresponding standards on nanozyme research. Therefore, nanozymes performance should be fully normalization according to their size, shape, modification to compare with each other when used for disease imaging diagnosis.

\section{AUTHOR CONTRIBUTIONS}

PW, TW, ML, and XY researched the literature and wrote the review. All authors revised and polished the review.

\section{FUNDING}

This work was supported by the National Key R\&D Program of China (2017YFA0205501), the National Natural Science Foundation of China (81722024 and 81571728), the Key Research Program of Frontier Sciences (QYZDY-SSWSMC013), and the Youth Innovation Promotion Association (2014078).

\section{SUPPLEMENTARY MATERIAL}

The Supplementary Material for this article can be found online at: https://www.frontiersin.org/articles/10.3389/fbioe. 2020.00015/full\#supplementary-material

CNS hematologic malignancies. Neurology 68, 1674-1679. doi: 10.1212/01.wnl. 0000261909.28915.83

Chen, F., Bai, M., Cao, K., Zhao, Y., Wei, J., and Zhao, Y. (2017). Fabricating $\mathrm{MnO} 2$ nanozymes as intracellular catalytic DNA circuit generators for versatile imaging of base-excision repair in living cells. Adv. Funct. Mater. 27:1702748. doi: 10.1002/adfm.201702748

Chen, T., Zou, H., Wu, X., Liu, C., Situ, B., Zheng, L., et al. (2018). Nanozymatic antioxidant system based on MoS2 nanosheets. ACS Appl. Mater. Interfaces 10, 12453-12462. doi: 10.1021/acsami.8b01245

Chi, M., Chen, S., Zhong, M., Wang, C., and Lu, X. (2018). Self-templated fabrication of FeMnO3 nanoparticle-filled polypyrrole nanotubes for peroxidase mimicking with a synergistic effect and their sensitive 
colorimetric detection of glutathione. Chem. Comm. 54, 5827-5830. doi: $10.1039 / \mathrm{c} 8 \mathrm{cc} 01574 \mathrm{k}$

Comotti, M., Della Pina, C., Matarrese, R., and Rossi, M. (2004). The catalytic activity of "naked" gold particles. Angew. Chem. Int. Ed. 43, 5812-5815. doi: 10.1002/anie.200460446

Dai, Z., Liu, S., Bao, J., and Ju, H. (2009). Nanostructured FeS as a mimic peroxidase for biocatalysis and biosensing. Chemistry 15, 4321-4326. doi: 10.1002/chem. 200802158

Dillner, J., Rebolj, M., Birembaut, P., Petry, K. U., Szarewski, A., Munk, C., et al. (2008). Long term predictive values of cytology and human papillomavirus testing in cervical cancer screening: joint European cohort study. BMJ 337:a1754. doi: 10.1136/bmj.a1754

Ding, H., Cai, Y., Gao, L., Liang, M., Miao, B., Wu, H., et al. (2019). Exosomelike nanozyme vesicles for $\mathrm{H} 2 \mathrm{O} 2$-responsive catalytic photoacoustic imaging of xenograft nasopharyngeal carcinoma. Nano Lett. 19, 203-209. doi: 10.1021/acs. nanolett.8b03709

Dong, J., Song, L., Yin, J. J., He, W., Wu, Y., Gu, N., et al. (2014). Co3O4 nanoparticles with multi-enzyme activities and their application in immunohistochemical assay. ACS Appl. Mater. Interfaces 6, 1959-1970. doi: 10.1021/am405009f

Duan, D., Fan, K., Zhang, D., Tan, S., Liang, M., Liu, Y., et al. (2015). Nanozymestrip for rapid local diagnosis of Ebola. Biosens. Bioelectron. 74, 134-141. doi: 10.1016/j.bios.2015.05.025

Fan, J., Yin, J. J., Ning, B., Wu, X., Hu, Y., Ferrari, M., et al. (2011). Direct evidence for catalase and peroxidase activities of ferritin-platinum nanoparticles. Biomaterials 32, 1611-1618. doi: 10.1016/j.biomaterials.2010.1 1.004

Fan, K., Cao, C., Pan, Y., Lu, D., Yang, D., Feng, J., et al. (2012). Magnetoferritin nanoparticles for targeting and visualizing tumour tissues. Nat. Nanotechnol. 7 , 459-464. doi: 10.1038/nnano.2012.90

Fan, K., Wang, H., Xi, J., Liu, Q., Meng, X., Duan, D., et al. (2017). Optimization of $\mathrm{Fe} 3 \mathrm{O} 4$ nanozyme activity via single amino acid modification mimicking an enzyme active site. Chem. Comm. 53, 424-427. doi: 10.1039/c6cc08542c

Fan, K., Xi, J., Lei, F., Wang, P., Zhu, C., Yan, T., et al. (2018). In vivo guiding nitrogen-doped carbon nanozyme for tumor catalytic therapy. Nat. Commun. 9:1440. doi: 10.1038/s41467-018-03903-8

Farhadi, K., Forough, M., Pourhossein, A., and Molaei, R. (2014). Highly sensitive and selective colorimetric probe for determination of L-cysteine in aqueous media based on Ag/Pd bimetallic nanoparticles. Sens. Actuators. B Chem. 202, 993-1001. doi: 10.1039/C4TA03990D

Gao, L., and Yan, X. (2016). Nanozymes: an emerging field bridging nanotechnology and biology. Sci. China. Life Sci. 59, 400-402. doi: 10.1007/s11427-016-5044-3

Gao, L., Zhuang, J., Nie, L., Zhang, J., Zhang, Y., Gu, N., et al. (2007). Intrinsic peroxidase-like activity of ferromagnetic nanoparticles. Nat. Nanotechnol. 2, 577-583. doi: 10.1038/nnano.2007.260

Ge, S., Liu, F., Liu, W., Yan, M., Song, X., and Yu, J. (2014). Colorimetric assay of K562 cells based on folic acid-conjugated porous bimetallic Pd@Au nanoparticles for point-of-care testing. Chem. Comm. 50, 475-477. doi: 10.1039/c3cc47622g

Hao, J. J., Qiu, Y. N., Zhou, D. F., Xiao, Y., Liu, Q., and Jin, R. M. (2011). Comparisons of clinical features of chronic aplastic anemia and myelodysplastic syndrome in children. China. J. Contem. Pedia 13, 867-869. doi: 10.1111/j.16000714.2011.01024.x

He, S., Shi, W., Zhang, X., Li, J., and Huang, Y. (2010). $\beta$ - cyclodextrinsbased inclusion complexes of $\mathrm{CoFe} 2 \mathrm{O} 4$ magnetic nanoparticles as catalyst for the luminol chemiluminescence system and their applications in hydrogen peroxide detection. Talanta 82, 377-383. doi: 10.1016/j.talanta.2010. 04.055

Herget, K., Hubach, P., Pusch, S., Deglmann, P., Götz, H., Gorelik, T. E., et al. (2017). Haloperoxidase mimicry by $\mathrm{CeO} 2$-x nanorods combats biofouling. $A d v$. Mater. 29:1603823. doi: 10.1002/adma.201603823

Hu, A. L., Deng, H. H., Zheng, X. Q., Wu, Y. Y., Lin, X. L., Liu, A. L., et al. (2017). Self-cascade reaction catalyzed by $\mathrm{CuO}$ nanoparticle-based dual-functional enzyme mimics. Biosens. Bioelectron. 97, 21-25. doi: 10.1016/j.bios.2017.05.037

Hu, D., Sheng, Z., Fang, S., Wang, Y., Gao, D., Zhang, P., et al. (2014). Folate receptor-targeting gold nanoclusters as fluorescence enzyme mimetic nanoprobes for tumor molecular colocalization diagnosis. Theranostics 4, 142153. doi: : 10.7150/thno.7266
Huang, X. L. (2018). Hydrolysis of phosphate esters catalyzed by inorganic iron oxide nanoparticles acting as biocatalysts. Astrobiology 18, 294-310. doi: 10. 1089/ast.2016.1628

Hyon Bin, N., Jung Hee, L., Kwangjin, A., Il, P. Y., Mihyun, P., In Su, L., et al. (2010). Development of a T1 contrast agent for magnetic resonance imaging using MnO nanoparticles. Angew. Chem. Int. Ed. 46, 5247-5247. doi: 10.1002/ ange.200604775

Jiang, B., Duan, D., Gao, L., Zhou, M., Fan, K., Tang, Y., et al. (2018). Standardized assays for determining the catalytic activity and kinetics of peroxidase-like nanozymes. Nat. Protoc. 13, 1506-1520. doi: 10.1038/s41596-018-0001-1

Jiang, X., Zhen, W., Liu, Y., Lin, L., and Tian, H. (2018). BSA-IrO2: Catalaselike nanoparticles with high photothermal conversion efficiency and X-Ray absorption coefficient for anti-inflammation and tumor theranostics. Angew. Chem. 130, 10309-10313. doi: 10.1002/ange.201804466

Jiang, B., Yan, L., Zhang, J., Zhou, M., Shi, G., Tian, X., et al. (2019). Biomineralization synthesis of the cobalt nanozyme in SP94-ferritin nanocages for prognostic diagnosis of hepatocellular carcinoma. ACS Appl. Mater. Interfaces 11, 9747-9755. doi: 10.1021/acsami.8b20942

Kim, M. I., Ye, Y., Woo, M. A., Lee, J., and Park, H. G. (2014). A highly efficient colorimetric immunoassay using a nanocomposite entrapping magnetic and platinum nanoparticles in ordered mesoporous carbon. Adv. Healthc. Mater. 3, 36-41. doi: 10.1002/adhm.201300100

Korschelt, K., Ragg, R., Metzger, C. S., Kluenker, M., Oster, M., Barton, B., et al. (2017). Glycine-functionalized copper (II) hydroxide nanoparticles with high intrinsic superoxide dismutase activity. Nanoscale 9, 3952-3960. doi: 10.1039/ c6nr09810j

Kuchma, M. H., Komanski, C. B., Colon, J., Teblum, A., Masunov, A. E., Alvarado, B., et al. (2010). Phosphate ester hydrolysis of biologically relevant molecules by cerium oxide nanoparticles. Nanomedicine 6, 738-744. doi: 10.1016/j.nano. 2010.05.004

Kwon, H. J., Cha, M. Y., Kim, D., Kim, D. K., Soh, M., Shin, K., et al. (2016). Mitochondria-targeting ceria nanoparticles as antioxidants for Alzheimer's disease. ACS Nano 10, 2860-2870. doi: 10.1021/acsnano.5b08045

Leng, B., Zou, L., Jiang, J., and Tian, H. (2009). Colorimetric detection of mercuric ion $(\mathrm{Hg} 2+)$ in aqueous media using chemodosimeter-functionalized gold nanoparticles. Sens. Actuators. B Chem. 140, 162-169. doi: 10.1016/j.snb. 2009.03.074

Li, B., Chen, D., Wang, J., Yan, Z., Jiang, L., Duan, D., et al. (2014). MOFzyme: intrinsic protease-like activity of Cu-MOF. Sci. Rep. 4:6759. doi: 10.1038/ srep06759

Li, J., Wang, J., Wang, Y., and Trau, M. (2017). Simple and rapid colorimetric detection of melanoma circulating tumor cells using bifunctional magnetic nanoparticles. Analyst 142, 4788-4793. doi: 10.1039/c7an01102d

Li, M., Lao, Y. H., Mintz, R. L., Chen, Z., Shao, D., Hu, H., et al. (2019). A multifunctional mesoporous silica-gold nanocluster hybrid platform for selective breast cancer cell detection using a catalytic amplification-based colorimetric assay. Nanoscale 11, 2631-2636. doi: 10.1039/c8nr08337a

Liang, F., Musto, C. J., and Suslick, K. S. (2010). A simple and highly sensitive colorimetric detection method for gaseous formaldehyde. J. Am. Chem. Soc. 132, 4046-4047. doi: 10.1021/ja910366p

Liang, M., and Yan, X. (2019). Nanozymes: from new concepts, mechanisms, and standards to applications. Acc. Chem. Res. 52, 2190-2200. doi: 10.1021/acs. accounts.9b00140

Lin, F., Tian, Y., Rong, Y., Lou, D., Zhang, X., Meng, W., et al. (2016). Enzyme catalysis enhanced dark-field imaging as a novel immunohistochemical method. Nanoscale 8, 8553-8558. doi: 10.1039/c5nr08232c

Lin, X. D., Liu, Y. Q., Tao, Z. H., Gao, J. T., Deng, J. K., Yin, J. J., et al. (2017). Nanozyme-based bio-barcode assay for high sensitive and logic-controlled specific detection of multiple DNAs. Biosens. Bioelectron. 94, 471-477. doi: 10.1016/j.bios.2017.01.008

Liu, F., Lin, L., Zhang, Y., Wang, Y., Sheng, S., Xu, C., et al. (2019). A tumormicroenvironment-activated nanozyme-mediated theranostic nanoreactor for imaging-guided combined tumor therapy. Adv. Mater. 31:1902885. doi: 10. 1002/adma.201902885

Liu, Y., Zheng, Y., Chen, Z., Qin, Y., and Guo, R. (2019). Highperformance integrated enzyme cascade bioplatform based on protein-BiPt nanochain@graphene oxide hybrid guided one-pot self-assembly strategy. Small 15:1804987. doi: 10.1002/smll.201804987 
Liu, Y., Zhu, G., Bao, C., Yuan, A., and Shen, X. (2014). Intrinsic peroxidase-like activity of porous $\mathrm{CuO}$ micro-/nanostructures with clean surface. Chinese J. Chem. 32, 151-156. doi: 10.1002/cjoc.201300683

Maji, S. K., Mandal, A. K., Nguyen, K. T., Borah, P., and Zhao, Y. (2015). Cancer cell detection and therapeutics using peroxidase-active nanohybrid of gold nanoparticle-loaded mesoporous silica-coated graphene. ACS Appl. Mater. Interfaces 7, 9807-9816. doi: 10.1021/acsami.5b01758

Mondal, S. S., and Holdt, H. J. (2016). Breaking down chemical weapons by metalorganic frameworks. Angew. Chem. 55, 42-44. doi: 10.1002/anie.201508407

Mosterd, K., Van Marion, A., and Van Steensel, M. A. (2008). Neonatal langerhans' cell histiocytosis: a rare and potentially life-threatening disease. Int. J. Dermatol. 47, 10-12. doi: 10.1111/j.1365-4632.2008. 03950.x

Mu, J., Wang, Y., Zhao, M., and Zhang, L. (2012). Intrinsic peroxidase-like activity and catalase-like activity of Co3O4 nanoparticles. Chem. Comm. 48, 2540-2542. doi: $10.1039 / \mathrm{c} 2 \mathrm{cc} 17013 \mathrm{~b}$

Natalio, F., Andre, R., Hartog, A. F., Stoll, B., Jochum, K. P., Wever, R., et al. (2012). Vanadium pentoxide nanoparticles mimic vanadium haloperoxidases and thwart biofilm formation. Nat. Nanotechnol. 7, 530-535. doi: 10.1038/ nnano.2012.91

Nath, I., Chakraborty, J., and Verpoort, F. (2016). Metal organic frameworks mimicking natural enzymes: a structural and functional analogy. Chem. Soc. Rev. 45, 4127-4170. doi: 10.1039/c6cs00047a

Nirala, N. R., Khandelwal, G., Kumar, B., Prakash, R., and Kumar, V. (2017). One step electro-oxidative preparation of graphene quantum dots from wood charcoal as a peroxidase mimetic. Talanta 173, 36-43. doi: 10.1016/j.talanta. 2017.05.061

Peng, C., Hua, M. Y., Li, N. S., Hsu, Y. P., Chen, Y. T., Chuang, C. K., et al. (2019). A colorimetric immunosensor based on self-linkable dual-nanozyme for ultrasensitive bladder cancer diagnosis and prognosis monitoring. Biosens. Bioelectron. 126, 581-589. doi: 10.1016/j.bios.2018.11.022

Qian, B., and Jiao, L. (2017). Application of multiplexed immunofluorescent staining and multi-spectral imaging in histological studies. China. J. His. Cyt. 26, 373-382. doi: 10.16705/j.cnki.1004-1850.04.010

Ragg, R., Natalio, F., Tahir, M. N., Janssen, H., Kashyap, A., Strand, D., et al. (2014). Molybdenum trioxide nanoparticles with intrinsic sulfite oxidase activity. ACS Nano 8, 5182-5189. doi: 10.1021/nn501235j

Roy, P., Lin, Z. H., Liang, C. T., and Chang, H. T. (2012). Synthesis of enzyme mimics of iron telluride nanorods for the detection of glucose. Chem. Comm. 48, 4079-4081. doi: 10.1039/c2cc30833a

Sahoo, P. C., Jang, Y. N., and Lee, S. W. (2013). Enhanced biomimetic CO2 sequestration and $\mathrm{CaCO} 3$ crystallization using complex encapsulated metal organic framework. J. Cryst. Growth. 373, 96-101. doi: 10.1016/j.jcrysgro.2012. 11.043

Santhosh, M., Chinnadayyala, S. R., Kakoti, A., and Goswami, P. (2014). Selective and sensitive detection of free bilirubin in blood serum using human serum albumin stabilized gold nanoclusters as fluorometric and colorimetric probe. Biosens. Bioelectron. 59, 370-376. doi: 10.1016/j.bios.2014.04.003

Schiffman, M., Herrero, R., Hildesheim, A., Sherman, M. E., Bratti, M., Wacholder, S., et al. (2000). HPV DNA testing in cervical cancer screening - results from women in a high-risk province of costa rica. JAMA 283, 87-93. doi: 10.1001/ jama.283.1.87

Singh, N., Savanur, M. A., Srivastava, S., D’Silva, P., and Mugesh, G. (2017). A redox modulatory $\mathrm{Mn3O} 4$ nanozyme with multi-enzyme activity provides efficient cytoprotection to human cells in a Parkinson's disease model. Angew. Chem. 56, 14267-14271. doi: 10.1002/ange.201708573

Su, H., Liu, D. D., Zhao, M., Hu, W. L., Xue, S. S., Cao, Q., et al. (2015). Dualenzyme characteristics of polyvinylpyrrolidone-capped iridium nanoparticles and their cellular protective effect against $\mathrm{H} 2 \mathrm{O} 2$-induced oxidative damage. ACS Appl. Mater. Interfaces 7, 8233-8242. doi: 10.1021/acsami.5b 01271

Su, L., Dong, W., Wu, C., Gong, Y., Zhang, Y., Li, L., et al. (2017). The peroxidase and oxidase-like activity of $\mathrm{NiCo} 2 \mathrm{O} 4$ mesoporous spheres: Mechanistic understanding and colorimetric biosensing. Anal. Chim. Acta 951, 124-132. doi: 10.1016/j.aca.2016.11.035

Sun, M., Xu, L., Qu, A., Zhao, P., Hao, T., Ma, W., et al. (2018). Siteselective photoinduced cleavage and profiling of DNA by chiral semiconductor nanoparticles. Nat. Chem. 10, 821-830. doi: 10.1038/s41557-018-0083-y
Talib, P., Dowding, J. M., Sanjay, S., Brian, W., Eric, H., Karakoti, A. S., et al. (2010). Nanoceria exhibit redox state-dependent catalase mimetic activity. Chem. Comm. 46, 2736-2738. doi: 10.1039/B922024K

Tarnuzzer, R. W., Colon, J., Patil, S., and Seal, S. (2005). Vacancy engineered ceria nanostructures for protection from radiation-induced cellular damage. Nano Lett. 5, 2573-2577. doi: 10.1021/nl052024f

Tian, L., Qi, J. X., Qian, K., Oderinde, O., Cai, Y. Y., Yao, C., et al. (2018). An ultrasensitive electrochemical cytosensor based on the magnetic field assisted binanozymes synergistic catalysis of $\mathrm{Fe} 3 \mathrm{O} 4$ nanozyme and reduced graphene oxide/molybdenum disulfide nanozyme. Sens. Actuators. B Chem. 260, 676684. doi: 10.1016/j.snb.2018.01.092

Tianran, L., Liangshuang, Z., Liangqia, G., Fengfu, F., and Guonan, C. (2014). Seeing diabetes: visual detection of glucose based on the intrinsic peroxidaselike activity of MoS2 nanosheets. Nanoscale 6, 11856-11862. doi: 10.1039/ c4nr03393k

Tokuyama, H., Yamago, S., Nakamura, E., Shiraki, T., and Sugiura, Y. (1993). Photoinduced biochemical activity of fullerene carboxylic acid. J. Am. Chem. Soc. 115, 7918-7919. doi: 10.1021/ja00070a064

Tonga, G. Y., Jeong, Y., Duncan, B., Mizuhara, T., Mout, R., Das, R., et al. (2015). Supramolecular regulation of bioorthogonal catalysis in cells using nanoparticle-embedded transition metal catalysts. Nat. Chem. 7, 597-603. doi: 10.1038/nchem.2284

Venugopal, S. B., and Prasad, S. (2015). Cytological diagnosis of osteoblastoma of cervical spine: a case report with review of literature. Diagn. Cytopathol. 43, 218-221. doi: $10.1002 /$ dc. 23175

Vernekar, A. A., Das, T., and Mugesh, G. (2016). Vacancy-engineered nanoceria: enzyme mimetic hotspots for the degradation of nerve agents. Angew. Chem. 55, 1412-1416. doi: 10.1002/ange.201510355

Wang, C. I., Chen, W. T., and Chang, H. T. (2012). Enzyme mimics of Au/Ag nanoparticles for fluorescent detection of acetylcholine. Anal. Chem. 84, 97069712. doi: 10.1021/ac300867s

Wang, W., Jiang, X., and Chen, K. (2012). Iron phosphate microflowers as peroxidase mimic and superoxide dismutase mimic for biocatalysis and biosensing. Chem. Comm. 48, 7289-7291. doi: 10.1039/c2cc32 $429 \mathrm{f}$

Wang, F., Zhang, Y., Du, Z., Ren, J., and Qu, X. (2018). Designed heterogeneous palladium catalysts for reversible light-controlled bioorthogonal catalysis in living cells. Nat. Commun. 9:1209. doi: 10.1038/s41467-018-03 617-x

Wang, T., He, J., Duan, D., Jiang, B., Wang, P., Fan, K., et al. (2019). Bioengineered magnetoferritin nanozymes for pathological identification of high-risk and ruptured atherosclerotic plaques in humans. Nano Res. 12, 863-868. doi: 10. 1021/acsnano. 5b07408

Wang, T., Wang, J., Ye, Y., Ping, S., Yi, Y., Wang, T., et al. (2017). Co3O4/reduced graphene oxide nanocomposites as effective phosphotriesterase mimetics for degradation and detection of paraoxon. Ind. Eng. Chem. Res. 56, 9762-9769. doi: 10.1021/acs.iecr.7b02223

Wang, X., Liu, D., Li, J., Zhen, J., and Zhang, H. (2015). Clean synthesis of Cu2O@CeO2 core@shell nanocubes with highly active interface. NPG Asia. Mater. 7:e158. doi: 10.1038/am.2014.128

Wang, Y. L., Zhang, Y., Su, Y., Li, F., Ma, H. M., Li, H., et al. (2014). Ultrasensitive non-mediator electrochemical immunosensors using $\mathrm{Au} / \mathrm{Ag} / \mathrm{Au}$ core/double shell nanoparticles as enzyme-mimetic labels. Talanta 124, 60-66. doi: 10.1016/ j.talanta.2014.02.035

Wei, L., Yu-Sang, L., Jing, Y., Lihua, Z., Zhengdan, L., Heqing, T., et al. (2010). Ultrasensitive fluorometric determination of hydrogen peroxide and glucose by using multiferroic BiFeO3 nanoparticles as a catalyst. Talanta 81, 901-907. doi: 10.1016/j.talanta.2010.01.035

Wu, L., Li, G. H., Xu, X., Zhu, L., Huang, R. M., and Chen, X. Q. (2019). Application of nano-ELISA in food analysis: recent advances and challenges. Trends. Anal. Chem. 113, 140-156. doi: 10.1016/j.trac.2019.02.002

Wu, Y., Song, M., Xin, Z., Zhang, X., Zhang, Y., Wang, C., et al. (2011). Ultra-small particles of iron oxide as peroxidase for immunohistochemical detection. Nanotechnology 22:225703. doi: 10.1088/0957-4484/22/22/22 5703

Xing, L., Qi, W., Huihui, Z., Lichun, Z., Yingying, S., and Yi, L. (2012). BSAtemplated $\mathrm{MnO} 2$ nanoparticles as both peroxidase and oxidase mimics. Analyst 137, 4552-4558. doi: 10.1039/C2AN35700C 
Xue, J., Song, H., Zhao, H., Wei, B., Zhang, L., and Yi, L. (2012). Well-redispersed ceria nanoparticles: promising peroxidase mimetics for $\mathrm{H} 2 \mathrm{O} 2$ and glucose detection. Anal. Methods 4, 3261-3267. doi: 10.1039/c2ay25511a

Yang, F., Hu, S., Zhang, Y., Cai, X., Huang, Y., Wang, F., et al. (2012). A hydrogen peroxide-responsive $\mathrm{O} 2$ nanogenerator for ultrasound and magnetic-resonance dual modality imaging. Adv. Mater. 24, 5205-5211. doi: 10.1002/adma.201202367

Yang, Z., Zhong, Y., Tang, X., Li, J., and Gao, W. (2018). Nanozyme tags enabled chemiluminescence imaging immunoassay for multiplexed cytokine monitoring. Chem. Comm. 54, 13813-13816. doi: 10.1039/c8cc07779g

Yu, C. J., Chen, T. H., Jiang, J. Y., and Tseng, W. L. (2014). Lysozyme-directed synthesis of platinum nanoclusters as a mimic oxidase. Nanoscale 6, 9618-9624. doi: $10.1039 / \mathrm{c} 3 \mathrm{nr} 06896 \mathrm{j}$

Yu, T., Youhui, L., Zhenzhen, H., Jinsong, R., and Xiaogang, Q. (2013). Incorporating graphene oxide and gold nanoclusters: a synergistic catalyst with surprisingly high peroxidase-like activity over a broad $\mathrm{pH}$ range and its application for cancer cell detection. Adv. Mater. 25:2510. doi: 10.1002/adma. 201370115

Zhang, A., Pan, S., Zhang, Y., Chang, J., Cheng, J., Huang, Z., et al. (2019). Carbongold hybrid nanoprobes for real-time imaging, photothermal/photodynamic and nanozyme oxidative therapy. Theranostics 9, 3443-3458. doi: 10.7150/thno. 33266

Zhang, T., Cao, C., Tang, X., Cai, Y., Yang, C., and Pan, Y. (2016). Enhanced peroxidase activity and tumour tissue visualization by cobalt-doped magnetoferritin nanoparticles. Nanotechnology 28:045704. doi: 10.1088/13616528/28/4/045704

Zhang, W., Hu, S., Yin, J. J., He, W., Lu, W., Ma, M., et al. (2016). Prussian blue nanoparticles as multienzyme mimetics and reactive oxygen species scavengers. J. Am. Chem. Soc. 138, 5860-5865. doi: 10.1021/jacs.5b1 2070

Zhang, X., He, S., Chen, Z., and Huang, Y. (2013). CoFe2O4 nanoparticles as oxidase mimic-mediated chemiluminescence of aqueous luminol for sulfite in white wines. J. Agric. Food Chem. 61, 840-847. doi: 10.1021/jf3 041269

Zhang, Z., Liu, B., and Liu, J. (2017). Molecular imprinting for substrate selectivity and enhanced activity of enzyme mimics. Small 13, doi: 10.1002/smll. 201602730

Zhao, Y., Liang, M., Li, X., Fan, K., Xiao, J., Li, Y., et al. (2016). Bioengineered magnetoferritin nanoprobes for single-dose nuclear-magnetic resonance tumor imaging. ACS Nano 10, 4184-4191. doi: 10.1021/acsnano.5b0 7408

Zheng, C., Ke, W., Yin, T., and An, X. (2016). Intrinsic peroxidase-like activity and the catalytic mechanism of gold@ carbon dots nanocomposites. RSC Adv. 6, 35280-35286. doi: 10.1039/c6ra01917j

Conflict of Interest: The authors declare that the research was conducted in the absence of any commercial or financial relationships that could be construed as a potential conflict of interest.

Copyright (c) 2020 Wang, Wang, Hong, Yan and Liang. This is an open-access article distributed under the terms of the Creative Commons Attribution License (CC BY). The use, distribution or reproduction in other forums is permitted, provided the original author(s) and the copyright owner(s) are credited and that the original publication in this journal is cited, in accordance with accepted academic practice. No use, distribution or reproduction is permitted which does not comply with these terms. 